\title{
Approximation of Reciprocal-Cubic Functional Equation in Non-Archimedean Normed Space
}

\author{
Nawneet Hooda*, Shalini Tomar ${ }^{2}$ \\ ${ }^{1}$ Department of mathematics,DCRUST,sonepat,Haryana,India \\ ${ }^{2}$ Kanya Mahavidyalaya,Kharkhoda,Sonepat,Haryana,India
}

Available online at: www.isroset.org

Received:16/Sept./2018, Accepted:06/Oct/2018, Online: 31/Oct/2018

\begin{abstract}
The aim of this paper is to study the stability of reciprocal-cubic functional equation using direct method in non-Archimedean normed spaces.
\end{abstract}

Keywords- Generalized Hyers-Ulam stability, Reciprocal-cubic functional equation and non-archimedean normed spaces. Mathematical subject classification- 39B72, 39B82.

\section{Introduction}

The stability of different types of functional equation was studied by many mathematicians after Ulam[1] presented various unsolved problems in his famous talk in 1940.Ulam's problem was solved by Hyers [ 10 ], T. Aoki [ 2 ], Th.M.Rassias[ 13 ] and Gavruta[ 9 ] under different adaptations.After that several stability results for various functional equations in different spaces have been widely studied.

In 2010,K.Ravi and B.V. Senthil Kunar[17] introduced and proved the generalized Hyers-Ulam stability of the reciprocal functional equation

$$
f(x+y)=\frac{f(x) f(y)}{f(x)+f(y)}
$$

in the space of nonzero real numbers.It is easily seen that the reciprocal function $f(x)=\frac{a}{x}$ is a solution of the functional equation (1).

In 2014, kim and Bodaghi[5] introduced and proved the generalized Hyers-Ulam stability of the quadratic reciprocal functional equation

$$
\begin{aligned}
f(2 x+y)+f(2 x-y)= \\
\frac{2 f(x) f(y)(4 f(x)+f(y))}{(4 f(y)-f(x))^{2}}
\end{aligned}
$$

Recently, K.Ravi et al.[18] and Kim et al.[12] investigated the generalized Hyers-Ulam stability of the cubic reciprocal functional equations $\quad f(2 x+y)+f(2 x-y)=$

$$
\frac{4 f(x) f(y)\left(4 f(y)+3 f(x)^{2 / 3} f(y)^{2 / 3}\right)}{\left(4 f(y)^{2 / 3}-f(x)^{2 / 3}\right)^{3}}
$$

and

$f(2 x+y)+f(x+2 y)=$ $\frac{9 f(x) f(y)\left(f(x)+f(y)+2 f(x)^{1 / 3} f(y)^{1 / 3}\left(f(x)^{1 / 3}+f(y)^{1 / 3}\right)\right)}{\left(2 f(x)^{2 / 3}+2 f(y)^{2 / 3}+5 f(x)^{1 / 3} f(y)^{1 / 3}\right)^{3}}$

in non-Archimedean fields respectively.Some more results about the stability of various types of reciprocal functional equation can be studied from[6,14 - 16,19,20].

In this paper, we generalize equation (4) and investigate the generalized Hyers-Ulam stability of this reciprocal-cubic functional equation in the framework of non-Archimedean Normed spaces.

$$
\begin{aligned}
& \frac{f((k+1) x+k y)+f(k x+(k+1) y)}{f(x) f(y)}= \\
& \frac{\left(k^{3}+(k+1)^{3}\right)(f(x)+f(y))+3 k(2 k+1)(k+1)(f(x) f(y))^{\frac{1}{3}}\left(\mathrm{f}(\mathrm{x})^{\frac{1}{3}}+\mathrm{f}(\mathrm{y})^{\frac{1}{3}}\right)}{\left[k(k+1)\left(\mathrm{f}(\mathrm{x})^{\frac{2}{3}}+\mathrm{f}(\mathrm{y})^{\frac{2}{3}}\right)+(2 k(k+1)+1) \mathrm{f}(\mathrm{x})^{\frac{1}{3}} \mathrm{f}(\mathrm{y})^{\frac{1}{3}}\right]^{3}}
\end{aligned}
$$

It can be easily seen that the reciprocal-cubic function $f(x)=\frac{c}{x^{3}}$ is a solution of the reciprocal-cubic functional equation (5).

In section 2, we will discuss terminologies and definitions to be used throughout the paper.In section 3 , we will provide the generalized Hyers-Ulam stability of (5) in non-Archimedean Normed spaces. We will provide counter example for the generalized Hyers-Ulam stability of reciprocal-cubic functional equation for some special case.

\section{Preliminaries}

A Non-Archimedean field is a field $\mathrm{K}$ equipped with a function $|\diamond|: K \rightarrow R$ such that for any $\alpha, \beta \in K$ we have

- $|\alpha| \geq 0$ and equality holds if and only if $\alpha=0$,

- $|\alpha \beta|=|\alpha||\beta|$,

- $|\alpha+\beta| \leq \max \{|\alpha|,|\beta|\}$ (strict triangle inequality).

From above conditions, we have $|1|=|-1|=1$ and $|n| \leq 1$ for each integer $n$.Also if we set $|x|=1$ for all nonzero $x \in K$ and $|0|=0$, we have an non-Achimedean valuation on $\mathrm{K}$, called the trivial non-Achimedean valuation.In addition we assume that $|\diamond|$ is non trivial, i.e. 
there is an $\alpha_{o} \in K$ such that $\left|\alpha_{o}\right| \notin\{0,1\}$.

\subsection{Definition}

Let $X$ be a vector space over a field $K$ with a non-Archimedean valuation $|*|$. A function $\|*\|: X \rightarrow$ $[0, \infty)$ is called a non-Archimedean norm if the following conditions hold:

- $\|x\|=0$ if and only if $x=0$ for all $x \in X$;

- $\|r x\|=|r|\|x\|$ for all $r \in K$ and $x \in X$;

- the strong triangle inequality:

$\|x+y\| \leq \max \{\|x\|,\|y\|\}$ for all $x, y \in X$.

Then $(X,\|*\|)$ is called a non-Archimedean normed space.

\subsection{Definition}

Let $\left\{x_{n}\right\}$ be a sequence in a non-Archimedean normed space $\mathrm{X}$.

1 .

A sequence $\left\{x_{n}\right\}_{n=1}^{\infty}$ in a non-Archimedean space is a Cauchy sequence if and only if, the sequence $\left\{x_{n+1}-\right.$ $\left.x_{n}\right\}_{n=1}^{\infty}$ converges to zero.

2.

The sequence $\left\{x_{n}\right\}$ is said to be convergent if, for any $\varepsilon>0$, there are a positive integer $\mathrm{N}$ and $x \in X$ such that $\| x_{n}-$ $x \| \leq \varepsilon$ for all $n \geq N$. Then, the point $x \in X$ is called the limit of the sequence $\left\{x_{n}\right\}$, which is denoted by $\lim _{n \rightarrow \infty} x_{n}=x$.

3.

every Cauchy sequence in $\mathrm{X}$ converges, then the non-Archimedean normed space $X$ is called a non-Archimedean Banach space.

Throughout this paper, we consider that $\mathbf{X}$ and $\mathbf{Y}$ are a non-Archimedean field and a complete non-Archimedean field, respectively.Let us define the function $D_{f}: X \times X \rightarrow Y$ by

$D_{f}(x, y)=f((k+1) x+k y)+f(k x+(k+1) y)-$

$\frac{\left(k^{3}+(k+1)^{3}\right)(f(x)+f(y))+3 k(2 k+1)(k+1)(f(x) f(y))^{\frac{1}{3}}\left(\mathrm{f}(\mathrm{x})^{\frac{1}{3}}+\mathrm{f}(\mathrm{y})^{\frac{1}{3}}\right)}{2}$

$\left[k(k+1)\left(\mathrm{f}(\mathrm{x})^{\frac{2}{3}}+\mathrm{f}(\mathrm{y})^{\frac{2}{3}}\right)+(2 k(k+1)+1) \mathrm{f}(\mathrm{x})^{\frac{1}{3}} \mathrm{f}(\mathrm{y})^{\frac{1}{3}}\right]^{3}$

for all $x, y \in X$. Also let us assume numerator and denominator of equation (5) is non zero for all $x \in X$ and $x \neq y$.

\section{Stability of Functional Equation (5) in Non-Archimedean Space}

In this section, using direct method, we will prove the generalized Hyers-Ulam stability of cubic functional equation (5) in non-Archimedean normed spaces.

\subsection{Theorem}

Let $\Phi: X \times X \rightarrow Y$ be a function such that $\lim _{n \rightarrow \infty} \mid(2 k+$ 1) $\left.\right|^{(-3 n)} \Phi\left(\frac{x}{(2 k+1)^{(n+1)}}, \frac{x}{(2 k+1)^{(n+1)}}\right)=0$

for all $x, y \in X$ and suppose that $f: X \rightarrow Y$ be a mapping satisfying the following inequality

$$
\left|D_{f}(x, y)\right| \leq \Phi(x, y)
$$

for all $x, y \in X$.Then,the limit $C(x)=\lim _{n \rightarrow \infty}(2 k+$
$1)^{-3 n} f\left(\frac{x}{(2 k+1)^{n}}\right)$ exists for all $x \in X$ and defines a unique cubic reciprocal mapping $C: X \rightarrow Y$ such that for all $x \in X$, we have,

$|f(x)-C(x)| \leq$
$\max \left\{\frac{|(2 k+1)|^{-3 j}}{2} \Phi\left(\frac{x}{(2 k+1)^{j+1}}, \frac{x}{(2 k+1)^{j+1}}\right) ; j \in N \cup\{0\}\right\}$

Moreover if,

$|f(x)-C(x)| \leq$

$\lim _{j \rightarrow \infty} \lim _{n \rightarrow \infty} \max \left\{\frac{|(2 k+1)|^{-3(m+j)}}{2} \Phi\left(\frac{x}{(2 k+1)^{m+j+1}}, \frac{x}{(2 k+1)^{m+j+1}}\right) ; j \leq\right.$

$m<n+j\}=0$

then $C(x)$ is unique cubic reciprocal mapping satisfying (9).

Proof: Existence- Replacing $(x, y)$ by $(x, x)$ and substituting $x$ by $\frac{x}{(2 k+1)}$ in (8), we get $\mid f(x)-(2 k+$

1) $)^{-3} f\left(\frac{x}{(2 k+1)}\right) \mid \leq \frac{1}{2} \Phi\left(\frac{x}{(2 k+1)}, \frac{x}{(2 k+1)}\right)$

for all $x \in X$.In (11) replacing $x$ by $x /(2 k+1)^{n}$ and multiplying by $(2 k+1)^{-3 n}$,we obtain $\mid(2 k+$ $1)^{-3 n} f\left(\frac{x}{(2 k+1)^{n}}\right)-(2 k+1)^{-(3 n+3)} f\left(\frac{x}{(2 k+1)^{n+1}}\right) \mid$

$$
\leq \frac{1}{2}|(2 k+1)|^{-3 n} \Phi\left(\frac{x}{(2 k+1)^{n+1}}, \frac{x}{(2 k+1)^{n+1}}\right)
$$

From equations (7) and (12) we can say that the sequence $(2 k+1)^{-3 n} f\left(\frac{x}{(2 k+1)^{n}}\right)$ is a cauchy sequence.As $Y$ is complete,therefore the sequence $\left\{(2 k+1)^{-3 n} f\left(\frac{x}{(2 k+1)^{n}}\right)\right\}_{n \geq 1}$ is convergent also.Consider $C(x)=\lim _{n \rightarrow \infty}\left\{(2 k+1)^{-3 n} f\left(\frac{x}{(2 k+1)^{n}}\right)\right\}$.

Next by using induction, we can easily show that

$$
\begin{aligned}
& \left|(2 k+1)^{-3 n} f\left(\frac{x}{(2 k+1)^{n}}\right)-f(x)\right| \\
& \quad \leq \mid \sum_{j=0}^{n-1}\left\{(2 k+1)^{-3(j+1)} f\left(\frac{x}{(2 k+1)^{j+1}}\right)-(2 k+\right. \\
& \leq \max \left\{\mid(2 k+1)^{-3(j+1)} f\left(\frac{x}{(2 k+1)^{j+1}}\right)-(2 k+\right. \\
& \left.\quad 1)^{-3 j} f\left(\frac{x}{(2 k+1)^{j}}\right) \mid: 0 \leq j<n\right\} \\
& \leq \max \left\{\frac{|(2 k+1)|^{-3 j}}{2} \Phi\left(\frac{x}{(2 k+1)^{j+1}}, \frac{x}{(2 k+1)^{j+1}}\right): 0 \leq j<n\right\}
\end{aligned}
$$

for all $x \in X$ and $n \in N$. By taking limit $n \rightarrow \infty$ in (13) and using definition of $C(x)$, we can say that the inequality (9) is true.With the help of (7),(8)and again using definition of $C(x)$,for all $x, y \in X$, we can say that $\left|D_{C}(x, y)\right|$

$$
\begin{aligned}
& =\lim _{n \rightarrow \infty}\left|\frac{1}{(2 k+1)}\right|^{3 n}\left|D_{f}\left(\frac{x}{(2 k+1)^{n}}, \frac{y}{(2 k+1)^{n}}\right)\right| \\
& \leq \lim _{n \rightarrow \infty}\left|\frac{1}{(2 k+1)}\right|^{3 n} \Phi\left(\frac{x}{(2 k+1)^{n}}, \frac{y}{(2 k+1)^{n}}\right)=0 .
\end{aligned}
$$

Thus ,the mapping $C(x)$ satisfies(5) and hence it is a cubic-reciprocal functional equation.

Uniqueness-To prove the uniqueness of $\mathrm{C}$, let $Q: X \rightarrow Y$ be another function which satisfies (9).Then,for all $x \in X$ 


$$
\begin{aligned}
& |C(x)-Q(x)|=\lim _{j \rightarrow \infty}|(2 k+1)|^{-3 j} \mid C\left(\frac{x}{(2 k+1)^{j}}\right) \\
& -Q\left(\frac{x}{(2 k+1)^{j}}\right) \mid \\
& \leq \lim _{j \rightarrow \infty}|(2 k+1)|^{-3 j} \max \left\{\mid C\left(\frac{x}{(2 k+1)^{j}}\right)\right. \\
& \left.-f\left(\frac{x}{(2 k+1)^{j}}\right)|,| f\left(\frac{x}{(2 k+1)^{j}}\right)-Q\left(\frac{x}{(2 k+1)^{j}}\right) \mid\right\} \\
& \leq \lim _{j \rightarrow \infty} \lim _{n \rightarrow \infty} \max \left\{\frac { | ( 2 k + 1 ) | ^ { - 3 ( m + j ) } } { 2 } \Phi \left(\frac{x}{(2 k+1)^{m+j+1}},\right.\right. \\
& \left.\left.\frac{x}{(2 k+1)^{m+j+1}}\right) ; j \leq m<n+j\right\}=0
\end{aligned}
$$

therefore $C=Q$.Hence the proof.

\subsection{Theorem}

Let $\Phi: X \times X \rightarrow Y$ be a function such that

$\lim _{n \rightarrow \infty}|(2 k+1)|^{3 n} \Phi\left((2 k+1)^{n} x,(2 k+1)^{n} x\right)=0(14)$

for all $x, y \in X$ and suppose that $f: X \rightarrow Y$ be a mapping satisfying the inequality (8) for all $x, y \in X$. Then,the limit $C(x)=\lim _{n \rightarrow \infty}(2 k+1)^{3 n} f\left(x(2 k+1)^{n}\right)$ exists for all $x \in X$ and defines a unique cubic reciprocal mapping $C: X \rightarrow Y$ such that for all $x \in X$

$|f(x)-C(x)| \leq \max \left\{\frac{|(2 k+1)|^{3(j+1)}}{2} \Phi\left(x(2 k+1)^{j}, x(2 k+\right.\right.$ $\left.\left.1)^{j}\right) ; j \in N \cup\{0\}\right\}$. (15)

moreover if, $|f(x)-C(x)| \leq$

$$
\begin{aligned}
& \lim _{j \rightarrow \infty} \lim _{n \rightarrow \infty} \max \left\{\frac{|(2 k+1)|^{3(m+j+1)}}{2} \Phi((2 k+\right. \\
& \left.\left.1)^{m+j} x,(2 k+1)^{m+j} x\right) ; j \leq m<n+j\right\}=0
\end{aligned}
$$

then $C(x)$ is unique cubic reciprocal mapping satisfying (15).

Proof: Existence- Replacing $(x, y)$ by $(x, x)$ in (8) and multiplying by $(2 k+1)^{3}$, then applying same arguments as in previous theorem we can easily get the proof.

\subsection{Corollary}

Let $\varepsilon \geq 0$ and $a+b=p \neq-3$ be constants.If $f: X \rightarrow Y$ satisfies

$\left|D_{f}(x, y)\right|$

$=\left\{\begin{array}{lll}\varepsilon\left(|x|^{p}+|y|^{p}\right) & p<-3 & \text { or } p>-3 \\ \varepsilon\left(|x|^{a}|y|^{b}\right) & p<-3 \text { or } p>-3, \\ \varepsilon\left(|x|^{p / 2}|y|^{p / 2}+\left(|x|^{p}+|y|^{p}\right)\right) & p<-3 \text { or } p>-3\end{array}\right.$

for all $x \in X$,then there exists a unique cubic-reciprocal functional equation $C(x): X \rightarrow Y$ satisfying (5) and

$$
|C(x)-f(x)|= \begin{cases}\frac{\varepsilon|x|^{p}}{(2 k+1)^{p}} & p>-3 \\ \frac{\varepsilon(2 k+1)^{3}|x|^{p}}{\varepsilon|x|^{p}} & p<-3 \\ \frac{\varepsilon(2 k+1)^{p}}{2} & p>-3 \\ \frac{3 \varepsilon|x|^{p}}{2(2 k+1)^{3}|x|^{p}} & p<-3 \\ \frac{3 \varepsilon(2 k+1)^{3}|x|^{p}}{2} & p<-3\end{cases}
$$

for all $x \in X$.

Proof: Applying theorem 3.1 and 3.2 with appropriate choice of $\Phi(\mathrm{x}, \mathrm{y})$ we can get the desired result.

\section{Counter-examples}

In this section we will provide examples to show non-stability of functional equation (5) for $\mathrm{p}=-3$ and $\alpha=\frac{-1}{\mathrm{k}}$ in $\mathbf{R}$ with usual metric $|$.$| in corollary (3.3) using well-known$ counter example provided by $Z$. Gajda[8].Consider the function $\Phi: \mathrm{R}^{\mathrm{a}} \rightarrow \mathrm{R}$ defined as

$$
\Phi(x)= \begin{cases}\frac{\vartheta}{x^{3}} & \text { for } x \in(1, \infty) \\ \vartheta & \text { otherwise }\end{cases}
$$

where $\vartheta>0$ is a constant, and let for all $\mathrm{x} \in \mathrm{R}^{*}$ the function $\mathrm{f}: \mathrm{R}^{*} \rightarrow \mathrm{R}$ be defined as

$$
\mathrm{f}(\mathrm{x})=\sum_{\mathrm{n}=0}^{\infty} \frac{\Phi\left((2 \mathrm{k}+1)^{-\mathrm{n}} \mathrm{x}\right)}{(2 \mathrm{k}+1)^{3 \mathrm{n}}}
$$

\subsection{Theorem}

If $\mathrm{f}: \mathrm{R}^{*} \rightarrow \mathrm{R}$ as defined in (16) satisfies the functional inequality

$$
\left|D_{f}(x, y)\right| \leq \frac{2 \vartheta\left((2 k+1)^{3}+1\right)}{(2 k+1)^{3}-1}\left(|x|^{-3}+|y|^{-3}\right)
$$

for all $\mathrm{x} \in \mathrm{R}^{*}$.Then there do not exist a cubic reciprocal mapping $C: R^{*} \rightarrow R$ and a constant $\rho>0$ such that

for all $\mathrm{x} \in \mathrm{R}^{*}$.

$$
|f(x)-Q(x)| \leq \rho|x|^{-3}
$$

Proof: $|f(x)|=\left|\sum_{n=0}^{\infty} \frac{\Phi\left((2 k+1)^{-n} x\right)}{(2 k+1)^{3 n}}\right| \leq$

$$
\sum_{\mathrm{n}=0}^{\infty} \frac{\vartheta}{(2 \mathrm{k}+1)^{3 \mathrm{n}}}=\frac{(2 \mathrm{k}+1)^{3} \vartheta}{2 \mathrm{k}\left(4 \mathrm{k}^{2}+6 \mathrm{k}+3\right)} .
$$

Hence the function is bounded. If $\left(|x|^{-3}+|y|^{-3}\right) \geq 1$ then L.H.S. of (17) is less than $\frac{2 \vartheta\left((2 \mathrm{k}+1)^{3}+1\right)}{(2 \mathrm{k}+1)^{3}-1}$. Suppose that $0<\left(|x|^{-3}+|y|^{-3}\right)<1$.Then there exists a positive number m such that $\frac{1}{(2 \mathrm{k}+1)^{3(\mathrm{~m}+1)}} \leq\left(|\mathrm{x}|^{-3}+|\mathrm{y}|^{-3}\right) \leq \frac{1}{(2 \mathrm{k}+1)^{3 \mathrm{~m}}}$ Hence we can say that

$$
\begin{aligned}
& (2 \mathrm{k}+1)^{3 \mathrm{~m}}\left(|\mathrm{x}|^{-3}+|\mathrm{y}|^{-3}\right)<1 \\
& \text { or } \quad \frac{\mathrm{x}^{3}}{(2 \mathrm{k}+1)^{3 \mathrm{~m}}}>1, \frac{\mathrm{y}^{3}}{(2 \mathrm{k}+1)^{3 \mathrm{~m}}}>1
\end{aligned}
$$


or

$$
\frac{\mathrm{x}}{(2 \mathrm{k}+1)^{(\mathrm{m}-1)}}>(2 \mathrm{k}+1)>1, \frac{\mathrm{y}}{(2 \mathrm{k}+1)^{(\mathrm{m}-1)}}>(2 \mathrm{k}+
$$$$
\text { 1) }>1
$$

and consequently $\frac{(\mathrm{k}+1) \mathrm{x}+\mathrm{ky}}{(2 \mathrm{k}+1)^{(\mathrm{m}-1)}}>1, \frac{\mathrm{kx}+(\mathrm{k}+1) \mathrm{y}}{(2 \mathrm{k}+1)^{(\mathrm{m}-1)}}>1$. Therefore, for each $n=0,1,2, \ldots ., m-1$, we have

$$
\frac{(\mathrm{k}+1) \mathrm{x}+\mathrm{ky}}{(2 \mathrm{k}+1)^{\mathrm{n}}}>1, \frac{\mathrm{kx}+(\mathrm{k}+1) \mathrm{y}}{(2 \mathrm{k}+1)^{\mathrm{n}}}>1 \text {. }
$$

and $\quad \mathrm{D}_{\Phi}\left((2 \mathrm{k}+1)^{-\mathrm{n}} \mathrm{x},(2 \mathrm{k}+1)^{-\mathrm{n}} \mathrm{y}\right)=0$ for $\mathrm{n}=$ $0,1,2, \ldots, \mathrm{m}-1$.Using definition of functions $\mathrm{f}(\mathrm{x})$ and $\Phi(\mathrm{x})$, we can easily calculate that

$$
\begin{array}{r}
\left|D_{\mathrm{f}}(\mathrm{x}, \mathrm{y})\right| \leq 2 \sum_{\mathrm{n}=\mathrm{m}}^{\infty}\left(\vartheta /(2 \mathrm{k}+1)^{3 \mathrm{n}}\right)+ \\
\frac{\left(\sum_{\mathrm{n}=\mathrm{m}}^{\infty}\left(\vartheta /(2 \mathrm{k}+1)^{3 \mathrm{n}}\right)\right)^{3}\left[2\left(\mathrm{k}^{3}+(\mathrm{k}+1)^{3}\right)+6 \mathrm{k}(\mathrm{k}+1)(2 \mathrm{k}+1)\right]}{(2 \mathrm{k}(\mathrm{k}+1)+2 \mathrm{k}(\mathrm{k}+1)+1)^{3}\left(\sum_{\mathrm{n}=\mathrm{m}}^{\infty}\left(\vartheta /(2 \mathrm{k}+1)^{3 \mathrm{n}}\right)\right)^{2}} \\
\leq 2 \sum_{\mathrm{n}=\mathrm{m}}^{\infty}\left(\vartheta /(2 \mathrm{k}+1)^{3 \mathrm{n}}\right)\left(1+\frac{1}{(2 \mathrm{k}+1)^{3}}\right) \leq \\
\frac{2 \vartheta\left((2 \mathrm{k}+1)^{3}+1\right)}{(2 \mathrm{k}+1)^{3}-1}\left(|\mathrm{x}|^{-3}+|\mathrm{y}|^{-3}\right)
\end{array}
$$

for all $\mathrm{x} \in \mathrm{R}^{*}$.Hence (17) is proved.Next we claim that the cubic reciprocal functional equation is not stable for $p=-3$ in corollary (3.3).Assume that there exists a cubic reciprocal functional equation $\mathrm{Q}: \mathrm{R}^{*} \rightarrow \mathrm{R}$ satisfying (18).Therefore ,we have

$$
|f(x)| \leq(1+\rho)|x|^{-3}
$$

Next,we can choose a positive integer $r$ with $r \vartheta>\rho+1$.If $x \in\left(1,2^{r-1}\right)$ then $3^{-n} x \in(1, \infty)$ for all $n=0,1,2, \ldots . r-1$ and therefore

$$
\begin{aligned}
& \quad|\mathrm{f}(\mathrm{x})|=\left|\sum_{\mathrm{n}=0}^{\infty} \frac{\Phi\left((2 \mathrm{k}+1)^{\left.-\mathrm{n}_{\mathrm{x}}\right)}\right.}{(2 \mathrm{k}+1)^{3 \mathrm{n}}}\right| \geq \quad \sum_{\mathrm{n}=0}^{\mathrm{r}-1} \frac{(2 \mathrm{k}+1)^{3 \mathrm{n}_{\vartheta} / \mathrm{x}^{3}}}{(2 \mathrm{k}+1)^{3 \mathrm{n}}}= \\
& \frac{\mathrm{r} \vartheta}{\mathrm{x}^{3}}>(\rho+1) \mathrm{x}^{-3}
\end{aligned}
$$

which is contradiction to (20), which completes the proof.

\section{Acknowledgment}

The authors would like to thank the anonymous referees for their fruitful suggestions for the improvement of this paper.

\section{References}

[1]. S. M. Ulam,Problems in Modern Mathematics, Science Editions, JohnWiley and Sons, New York, NY, USA,1964.

[2]. T. Aoki,On the stability of the linear transformation in Banach spaces. J. Math. Soc. Jpn., vol. 2(1950),pp. 64-66.

[3]. H. Azadi Kenary, On the stability of a cubic functional equation in random normed spaces, J. Math. Ext., vol. 4, no. 1(2009), pp. 1 -11.

[4]. A Bodaghi,Y Ebrahimdoost, On the stability of quadratic reciprocal functional equation in non Archimedean fields. Asian-Eur. J. Math.,vol. 9,no. 1(2016), Article ID 1650002.

[5]. A Bodaghi,SO Kim, Approximation on the quadratic reciprocal functional equation. J. Funct. Spaces Appl. 2014, Article ID 532463.

[6]. A. Bodaghi,JM Rassias,C Park,Fundamental stabilities of an alternative quadratic reciprocal functional equation in non-Archimedean fields. Proc. Jangjeon Math. Soc. ,vol. 18, no.3(2015), pp. 313-320.

[7]. M. Eshaghi Gordji and M. B. Savadkouhi, Stability of mixed type cubic and quartic functional equations in random normed spaces, J. Inequal. Appl., 2009(2009), Article ID 527462, 9 pages.
[8]. Z. Gajda, On stability of additive mappings, Int. J. Math. Math. Sci.,vol. 14 (1991),pp. 431-434.

[9]. P. Gavruta,A generalization of the Hyers-Ulam-Rassias stability of approximately additive mappings,J. Math. Anal. Appl., vol. 184, no. 3(1994), pp. 431-436.

[10]. D. H. Hyers, On the stability of the linear functional equation, Proc. Natl. Acad. Sci. USA, vol. 27, no. 4(1941), pp. 222-224.

[11]. D. H. Hyers, G. Isac, and Th. M. Rassias, Stability of Functional Equations in Several Variables, Birkhauser, Basel, Switzerland, 1998.

[12]. S.O. Kim,B.V. Senthil Kumar,A. Bodaghi, Approximation on the reciprocal-cubic and reciprocal-quartic functional equations in non-archimedean fields,Adv. Differ. Equ., (2017) 2017: 77.

[13]. Th. M. Rassias, On the stability of the linear mapping in Banach spaces,Proc. Amer. Math. Soc., vol. 72, no. 2(1978), pp. 297-300.

[14]. K. Ravi, J. M. Rassias and B. V. Senthil Kumar, Ulam stability of generalized reciprocal functional equation in several variables, Int. J. Appl. Math. Stat. 19(D10) (2010) 119.

[15]. K. Ravi, J. M. Rassias and B. V. Senthil Kumar, Ulam stability of reciprocal difference and adjoint funtional equations, Australian J. Math. Anal.Appl. 8(1) (2011), Article ID: 13, 118.

[16]. K Ravi,JM Rassias,BV Senthil Kumar,A Bodaghi, Intuitionistic fuzzy stability of a reciprocal-quadratic functional equation, Int. J. Appl. Sci. Math. vol. 1,no. 1(2014),pp. 9-14.

[17]. K. Ravi,B.V. Senthil Kumar, Ulam-Gavruta- Rassias stability of Rassias reciprocal functional equation. Glob. J. Appl. Math. Math. Sci.,vol. 3,no. 1-2(2010),pp. 57-79.

[18]. K. Ravi,S. Suresh,Generalized Hyers-Ulam Stability of a Cubic reciprocal Functional Equation,British Journal of Mathematics and Computer Sciencevol. 20,no. 6(2017),pp. 1-9

[19]. K Ravi,E Thandapani,BV Senthil Kumar,Stability of reciprocal type functional equations. Panam. Math. J. vol. 21,no. 1(2011), pp. 59-70.

[20]. K. Ravi, E. Thandapani, B.V. Senthil Kumar,Solution and stability of a reciprocal type functional equation in several variables, $\mathbf{J}$. Nonlinear Sci. Appl., vol. 7 (2014),pp. 18-27.

\section{AUTHORS PROFILE:}

Dr. Nawneet Hooda is in the Department of Mathematics of DCRUST Murthal,Sonepat.His Area of interest is Functional Analysis.He has published Various research papers in reputed journals.

Mrs. Shalini Tomar is Assistant Professor of Mathematics in Kanya Mahavidyalaya, Kharkhoda,Sonepat.She is also persuing her Ph.D. in mathematics at the dept. of mathematics,DCRUST,Murthal,Sonepat. 